\title{
Geociências
}

\section{Estrutura subsuperficial do Complexo Alcalino do Mendanha, Rio de Janeiro, por integração de dados geológicos e gravimétricos}

\section{Subsurface structure of the Mendanha Alkaline Complex, Rio de Janeiro, Brazil, by integration of geologic and gravimetric data}

\section{Carlos Eduardo Miranda Mota \\ Geólogo M.Sc., \\ Universidade do Estado do Rio de Janeiro (UERJ). edu_geologia@hotmail.com \\ Mauro Cesar Geraldes \\ Geólogo D.Sc. \\ Universidade do Estado do Rio de Janeiro (UERJ). geraldes@uerj.br}

\section{Mauro Andrade de Sousa \\ Geofísico D. Sc., \\ Observatório Nacional (ON). \\ mauro@on.br}

\section{Miguel Angelo Mane}

Geofísico Ph.D.,

Universidade do Estado do Rio de Janeiro (UERJ) miguel@uerj.br

\section{Resumo}

Esse trabalho apresenta os resultados de pesquisas geológicas e gravimétricas realizadas na região do Complexo Alcalino do Mendanha. As técnicas aplicadas foram de mapeamento geológico básico 1:50.000 e gravimetria terrestre, com equipamentos LaCoste \& Romberg, com controle de posicionamento por GPS diferencial. A análise integrada dos dados permitiu gerar seções e modelos gravimétricos 2,5D, estimando a geometria da suíte alcalina em subsuperfície. O Complexo Alcalino do Mendanha é constituído por rochas de composição sienítica de granulometria variável, com predominância de álcali-sienitos, sienitos e rochas piroclásticas na região do "Vulcão de Nova Iguaçu" e de sienitos com nefelina, na região do Morro do Marapicu. Rochas sieníticas possuem densidade média de $2,54 \mathrm{~g} / \mathrm{cm}^{3}$ e rochas piroclásticas, $2,46 \mathrm{~g} / \mathrm{cm}^{3}$, medidas em laboratório. Em comparação com gnaisses encaixantes $(2,68 \mathrm{~g} /$ $\mathrm{cm}^{3}$ ), produzem anomalias gravimétricas negativas. $\mathrm{O}$ modelo gravimétrico da região do "Vulcão de Nova Iguaçu" ilustra uma geometria em forma de funil, formada por rochas sieníticas e uma estrutura colunar (conduto) de rochas piroclásticas. O modelo para o Morro do Marapicu apresenta uma estrutura convexa rasa, que é interpretada como continuidade do Mendanha. Com isso, o estágio de denudação atual caracteriza porção basal de câmara magmática, com exibição de conduto piroclástico e diques alimentadores.

Palavras-chave: Rochas alcalinas, Vulcão de Nova Iguaçu Complexo Alcalino do Mendanha, Gravimetria, Modelagem 2,5D.

\section{Abstract}

This paper presents the results of geologic and gravimetric surveys carried out in the area of the Mendanha Alkaline Complex. The applied techniques were: geological mapping and terrestrial gravimetric survey with LaCoste \& Romberg equipment and Differential GPS position control. The integrated analysis allowed for the building of 2.5D models and cross-sections, to estimate the geometry of the alkaline suite. The Mendanha Alkaline Complex is composed of siennite rocks with variable grain-size, with predominance of alkali-siennites, siennite and pyroclastic rocks in the region of the "Nova Iguacu Volcano" and nepheline-bearing siennites in the region of Morro do Marapicu. Siennitis rocks have an average bulk density of $2.54 \mathrm{~g} / \mathrm{cm}^{3}$ and the pyroclastic rocks about $2.46 \mathrm{~g} / \mathrm{cm}^{3}$, measured in the laboratory. 
In comparison with the host gneiss, with a bulk density of about $2.68 \mathrm{~g} / \mathrm{cm} 3$, these alkaline rocks have a negative gravimetric anomaly. The "Nova Iguacu Volcano" gravimetric model shows a funnel-like geometry of siennitic rocks with a columnar structure (conduct) of pyroclastic rocks. The Morro do Marapicu model shows a shallow convex structure and was interpreted as the continuation of Mendanha. Thereby, the current denudation stage is characterized by an eroded basal section of a magma chamber, with exposure of pyroclastic conduit and feeder dikes.

Keywords: Alkaline rocks, Nova Iguaçu Volcano, Mendanha Alkaline Complex, Gravimetry, 2,5D Modelling.

\section{Introdução}

O Complexo Alcalino do Mendanha é composto por um conjunto de elevações morfológicas, compostas pelas serras do Mendanha, Madureira e Gericinó e pelos morros do Marapicu e Manoel José (Figura 1), sustentados por rochas alcalinas saturadas a subsaturadas em sílica. Essas elevações contrastam

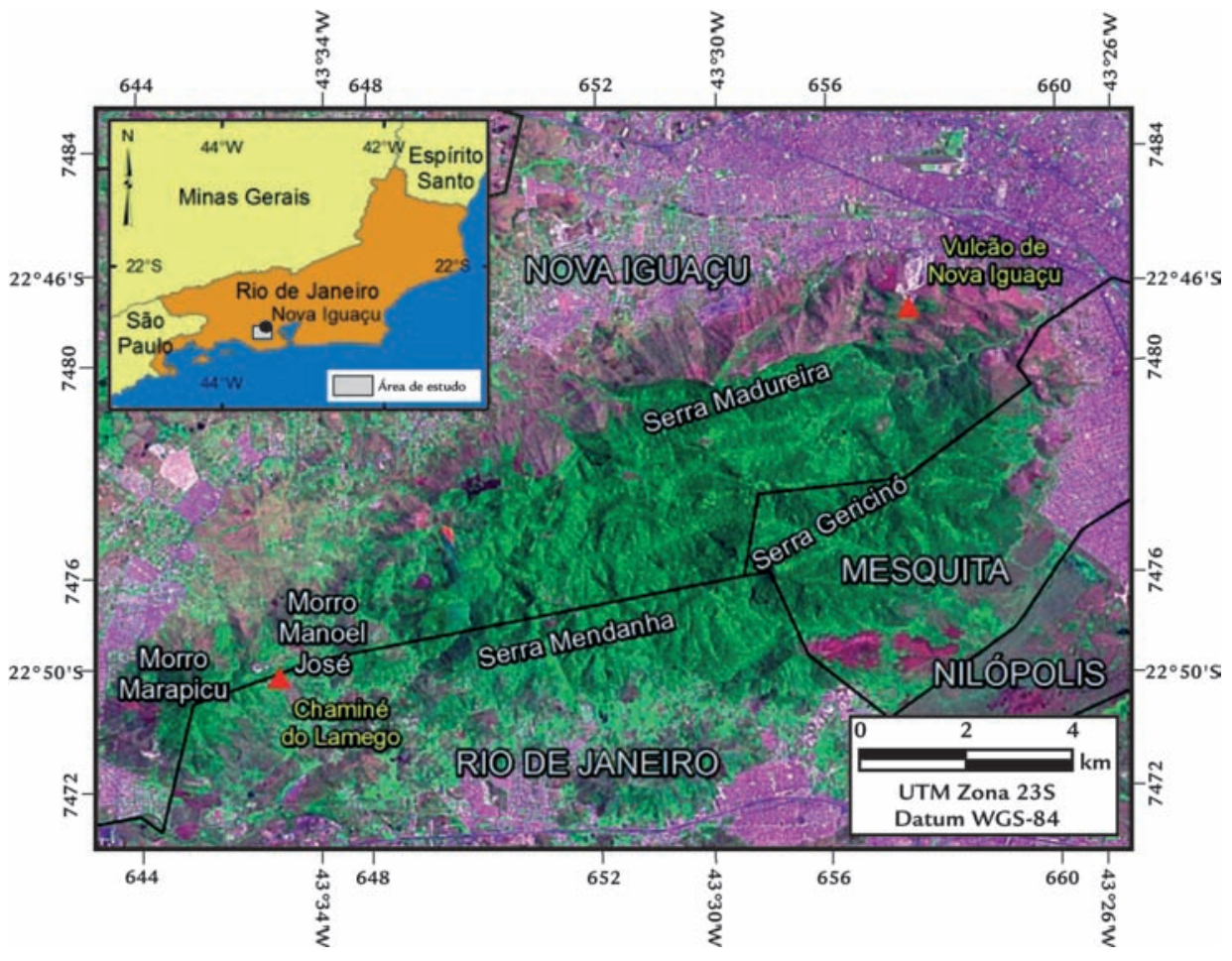

com as planícies da baixada Fluminense, por um desnível topográfico que chega a atingir em torno de $900 \mathrm{~m}$ acima do nível do mar. Esse maciço localiza-se entre os municípios de Nova Iguaçu e Rio de Janeiro, entre as coordenadas $43^{\circ} 26^{\prime} \mathrm{W}$ e $43^{\circ} 36^{\prime} \mathrm{W}$ de longitude e $22^{\circ} 45^{\prime} \mathrm{S}$ e $22^{\circ} 51^{\prime} S$ de latitude.
Esse trabalho mostra os resultados das pesquisas de geofísica terrestre e mapeamento geológico 1:50.000 do Complexo Alcalino e, a partir da integração dos dados, objetiva elucidar um modelo geométrico da intrusão alcalina.
Figura 1

Localização do Complexo Alcalino do Mendanha, com a localização das principais toponímias referentes à elevação montanhosa. Também estão representadas as localizações dos ditos "Vulcão de Nova Iguaçu" e "Chaminé do Lamego". Ao fundo, imagem de satélite LANDSAT 7 (ETM+), composição de bandas 742 (USGS, 2011).

\section{Materiais e métodos}

As convenções, para a realização da modelagem, foram a adoção de valores de densidade constantes para cada polígono, geometria $2 \mathrm{D}$, mas impondo uma largura finita no plano $\mathrm{XZ}$, de acordo com o método de Talwani et al. (1951). A modelagem direta usa um processo interativo para a confecção dos perfis gravimétricos residuais e, nessa modelagem, procurou-se atingir um melhor ajuste entre as anomalias observadas e calculadas.

Os produtos gerados foram os ma- pas das anomalias gravimétricas Ar-livre e Bouguer e a modelagem direta 2,5D, gerados a partir de anomalias Bouguer residuais, associados a dados geológicos e densidades, com o objetivo de se determinar a geometria em subsuperfície. Os gravímetros utilizados, na campanha, foram modelos LaCoste \& Romberg analógicos, modelos G602, G622 e G257. $\mathrm{Na}$ campanha, procurou-se manter uma grade de espaçamento de $1 \mathrm{~km}$ entre cada estação gravimétrica.

Foram utilizados receptores Trim- ble, modelo 4000SE, para o posicionamento das estações gravimétricas, através de DGPS (Differential GPS - GPS Diferencial). Os ajustes ao geoide foram realizados com base em Referências de Nível do IBGE (Arana, 2004). Os modelos obtidos referem-se às áreas do "Vulcão de Nova Iguaçu", localizadas na porção NE do Serra Madureira, e do morro do Marapicu, localizado na porção SW do maciço onde é descrito a "Chaminé do Lamego". A "Chaminé do Lamego" ocorre devido à presença de rochas piro- 
clásticas (Klein et al., 1984).

Para que os dados geofísicos possam ser interpretados corretamente, fezse necessário uma revisão na geologia do Complexo Alcalino do Mendanha. O único mapa publicado de todo o complexo foi publicado por Klein (1993) e é contestado por vários autores (e.g. Mota \& Geraldes, 2006, Motoki et al., 2007a). A escala adotada, no trabalho de mapeamento do Complexo, foi de 1:50.000, considerada conveniente para a diferenciação de fácies por diferenças de densidade.

O levantamento geológico, voltado para a correlação com informações gravimétricas, visou a delimitar o Complexo Alcalino do Mendanha das rochas gnáissicas encaixantes da Faixa Ribeira

\section{Contexto geológico}

O Complexo Alcalino do Mendanha faz parte da Província Alcalina do Sudeste Brasileiro ou Província Serra do Mar (Almeida 1983). Nessa província, são observadas, aproximadamente, 30 intrusões, formando três alinhamentos magmáticos: Poços de Caldas - Cabo Frio (WNW-ESE), Mendanha - Morro de São João (WSW-ENE); Monte de Trigo - Ilha de Vitória (WSW-ENE).

A maioria dessas intrusões é for-

\section{Resultados}

\section{Geologia de Campo}

O Complexo Alcalino do Mendanha possui variedades litológicas semelhantes em termos de mineralogia, porém variáveis em termos texturais, geralmente associado a diferentes velocidades de resfriamento (Figura 2). Os principais tipos de rocha são sienitos, traquitos e rochas extrusivas, tais como aglomerados e brechas piroclásticas, portando basicamente feldspato alcalino, anfibólio, biotita e sulfeto disseminado. Nefelina é rara, sendo que sua maior ocorrência situa-se no morro do Marapicu. Essa gama de tipos petrográficos e texturas é associada às diferentes velocidades de resfriamento do magma alcalino.

Nas bordas do corpo, são encontradas brechas intrusivas, sendo que se observa um aumento na proporção de fragmentos de rochas alcalinas em relação à de rochas encaixantes à medida que se segue da borda do corpo para o interior.

As rochas traquíticas afíricas e por- e a caracterizar as suas principais variações mineralógicas e texturais. Com isso, tornou-se possível determinar as variações de densidade das rochas e como essas variações estão distribuídas dentro do maciço.

O cálculo da densidade foi feito em planilhas eletrônicas com as medidas dos parâmetros de massa e volume das amostras. As amostras secas tiveram as suas massas aferidas em balanças digitais do Laboratório Geológico de Processamento de Amostras (LGPA - UERJ). O volume foi calculado da seguinte forma: as amostras secas foram mergulhadas em água, dentro de uma proveta com graduação lateral, abertura de seis centímetros $(6 \mathrm{~cm})$ de diâmetro e uma quantidade de água suficiente para cobrir a amostra. A amostra totalmente submersa no líquido provoca um deslocamento da coluna d'água, lido na régua da proveta, que representa o volume da amostra. Com os valores da massa da amostra e do volume de líquido deslocado, foi possível calcular a densidade dos litotipos.

O software utilizado, no tratamento do dado geofísico, foi o GEOSOFT Oasis Montaj 6.4.2 (GEOSOFT, 2007), acrescido dos módulos Gravity e GMSYS. O módulo Gravity foi utilizado para o tratamento dos dados gravimétricos, aplicação das correções e geração dos grids. O módulo GM-SYS foi utilizado para o cálculo do modelo gravimétrico, a partir dos perfis de anomalias gravimétricas residuais. Os mapas foram elaborados no ArcGIS 9.3 (ESRI, 2008). mada por nefelina-sienitos e sienitos e seus equivalentes vulcânicos, com variações texturais e granulométricas. O Complexo Alcalino do Mendanha possui idades do Cretáceo Superior, segundo datação K-Ar em rocha total (c.a. 72-56 Ma; Amaral et al., 1967; Sonoki \& Garda, 1988) e ${ }^{40} \mathrm{Ar}-{ }^{39} \mathrm{Ar}$ (Motoki et al., 2007a).

O Complexo Alcalino do Mendanha destaca-se entre outros complexos alcalinos por incluir litotipos com textura plutônica e hipabissal, além de estruturas que podem sugerir processos magmáticos rápidos e explosivos. Tais processos, possivelmente, são controlados por gases quentes ascendentes com fragmentos em suspensão (fluidificação), como proposto por Klein et al. (1984), Silveira et al. (2005), Motoki et al. (2007b; 2008a; c) e Sichel et al. (2008). firíticas localizam-se, preferencialmente, em regiões periféricas do Complexo Alcalino do Mendanha e os sienitos, em porções mais interiores. Quanto à composição mineralógica, não existem grandes diferenças e observou-se maior concentração de minerais máficos, na região do Morro do Marapicu, e eventuais presenças de vesículas. Entre os morros do Marapicu e Manoel José, ocorrem rochas gnáissicas do embasamento (Mota, 2007; Motoki et al., 2007a, 2008a; Mota et al., 2008).

As brechas piroclásticas ocorrem na porção NE do maciço e são, geralmente, constituídas de clastos de traquito, às vezes com amígdalas milimétricas preenchidas por sulfetos, carbonatos e fluorita. Os clastos, com até $10 \mathrm{~cm}$ de comprimento, apresentam borda de resfriamento de até $1 \mathrm{~cm}$. A matriz é formada por lapilli e cinza em proporções variáveis.

Os diques, geralmente, apresentam composição traquítica, raramente lamprofírica, com direção NE-SW e mergulhos subverticais, paralelos aos lineamentos observados em fotos aéreas, com exceção da porção NE do maciço, que mostra um padrão aleatório de atitude. Esses diques chegam a aflorar a distâncias de até $5 \mathrm{~km}$ do maciço e, provavelmente, permitiram que algumas elevações próximas resistissem à erosão. De acordo com Mota e Alves (2006), os diques alcalinos são os condicionantes principais do relevo, sendo mais resistentes ao intemperismo do que os sienitos. $\mathrm{O}$ alinhamento dos diques define as áreas escarpadas e ressaltos nas áreas periféricas.

O Complexo Alcalino do Mendanha é circundado por biotita gnaisses (ortoderivados e paraderivados) e migmatitos quartzo-feldspáticos, com raras ocorrências de enclaves de biotita gnaisses e gnaisses facoidais. Essa variedade de rochas encaixantes também foi 
encontrada dentro de brechas intrusivas. Esses gnaisses são pouco intemperizados nas proximidades do complexo, com

afloramentos em cotas de até $200 \mathrm{~m}$, chegando a $400 \mathrm{~m}$, de acordo com Dutra (2004), Silveira et al. (2005), Valente

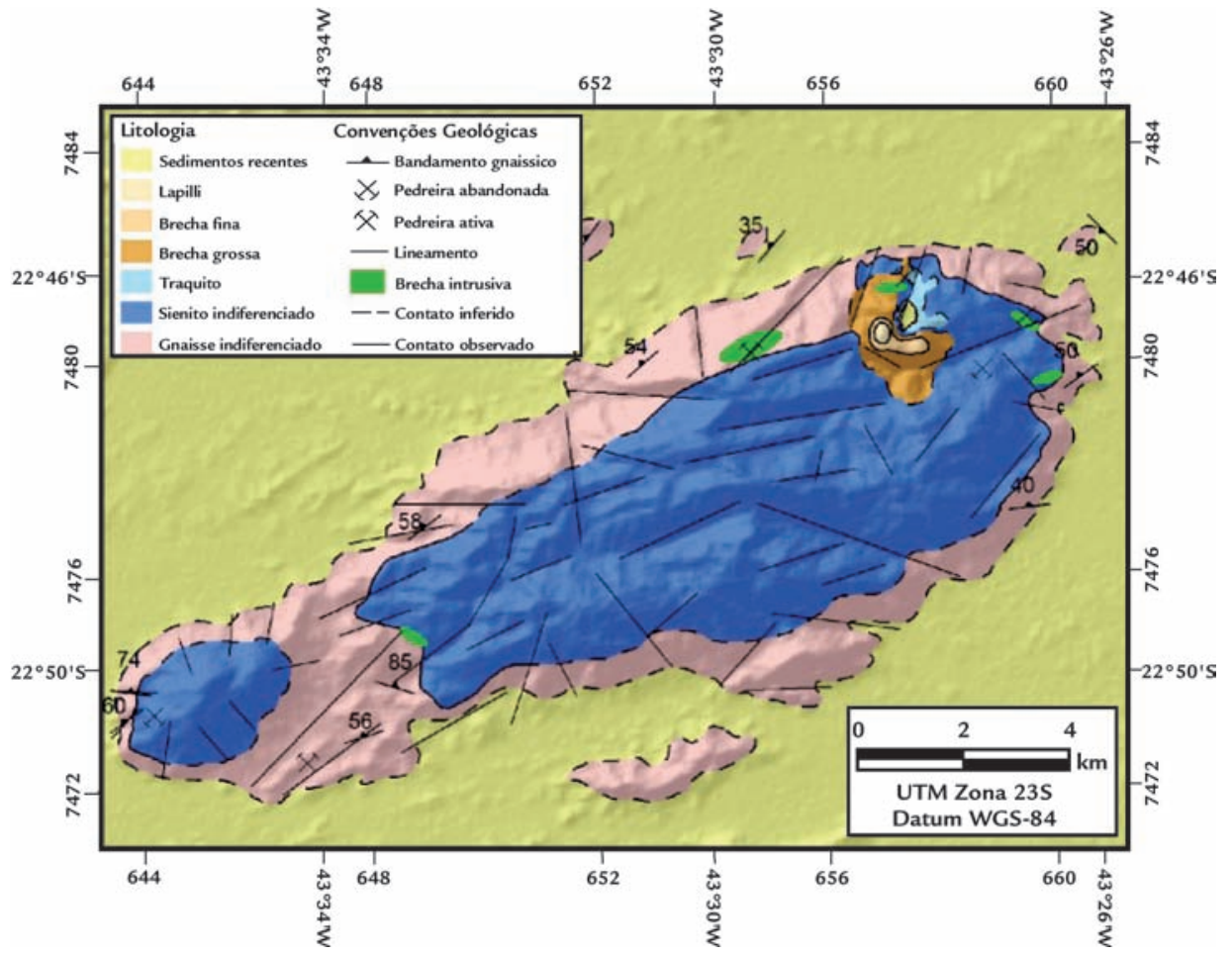

et al. (2005), Arena et al., (2005), Mota (2007), Mota et al. (2008), Motoki et al. (2007a; c; 2008a).
Figura 2

Mapa-base geológico 1:50.000 do Complexo Alcalino do Mendanha (Adaptado de Mota, 2007).

\section{Gravimetria}

Os mapas de anomalias gravimétricas foram confeccionados no programa GEOSOFT Oasis Montaj, através do método de interpolação tipo krigagem (Krigging), com intervalo de $200 \mathrm{~m}$ para os grids. Esse método de interpolação é o mais indicado para dados distribuídos aleatoriamente. Os dados de anomalias Ar-livre e Bouguer tratados e interpolados segundo uma distância estatística, sem tendências, de acordo com a concentração de estações gravimétricas, são apresentados nas Figuras 3 e 4.

Do ponto de vista geral, o Complexo Alcalino do Mendanha, em subsuperfície, possui as mesmas características geométricas do correspondente aflorante, ou seja, apresenta a mesma geometria elíptica, com eixo maior NE-SW, concordantes com os grandes lineamentos da Faixa Ribeira. A anomalia, nas redondezas do Complexo Alcalino do Mendanha, possui valores entre $-38 \mathrm{mGal}$ e -30 $\mathrm{mGal}$. No mapa de anomalias ar-livre da Figura 3, foi possível a identificação de duas anomalias distintas. A maior anomalia, localizada nas Serras do Gericinó e Mendanha, apresenta uma geometria elíptica, alongada no eixo NE-SW, e possui os valores mais extremos de anomalia referentes às rochas alcalinas, entre
$-28 \mathrm{mGal}$ a $11 \mathrm{mGal}$. A outra anomalia Ar-Livre é referente ao Marapicu, que possui geometria circular, com valores entre -30 mGal e - 24 mGal, e está circundada por valores associados às rochas encaixantes, que é coerente com o mapa geológico da Figura 2.

As anomalias Bouguer, já com as correções aplicadas, exibidas na Figura 4 , variam em intervalos diversificados, sendo que os menores valores estão na região central do mapa. Tais anomalias estão associadas às rochas alcalinas do Complexo Alcalino do Mendanha, com valores entre -37 mGal e -68 $\mathrm{mGal}$. Os maiores valores estão ligados às rochas do embasamento, com intervalos entre - $30 \mathrm{mGal}$ e $-17 \mathrm{mGal}$. São esboços de um padrão elíptico, como esperado para intrusões dessa natureza. $\mathrm{Na}$ região correspondente à $\mathrm{Ca}$ buçu (Nova Iguaçu), correspondente à porção noroeste do maciço e à porção sudeste, correspondente ao Campo do Gericinó, as curvas de anomalias apresentaram tendências circulares. Devido às características geológicas e a escassez de pontos de coleta na área, esta anomalia pode ter erros associados ao método de interpolação escolhido para gerar os grids.
A separação regional-residual da anomalia de Bouguer é importante para a concepção do modelo gravimétrico, pois, para a realização da modelagem direta, os dados que são utilizados são os dados residuais, ou seja, o componente regional do campo gravitacional é reduzido a uma superfície polinomial e removido. Para a estimativa do efeito gravimétrico regional e posterior separação foi aplicado o método de ajuste polinomial por mínimos quadrados, onde é encontrado o polinômio de superfície que melhor represente o comportamento regional dos dados.

O mapa da Figura 5 foi obtido pela remoção da superfície polinomial de grau 1 gerada a partir do mapa de anomalia Bouguer completa. Apesar de não representar exatamente o campo regional, possui maior semelhança com a curva de dados gravimétricos. Com a definição do mapa residual, foram determinados os valores correspondentes aos perfis $\mathrm{AB}$ e $\mathrm{CD}$, para a posterior modelagem direta 2,5D. Com o aumento do grau da superfície polinomial, houve um aumento da área dos valores em volta da anomalia. Comparando o campo observado com a representação do polinômio em uma análise quantita- 
Figura 3

Mapa de anomalias ar-livre do Complexo Alcalino do Mendanha e localização das estações gravimétricas. Valores em mGal.

Os contatos litológicos estão plotados no mapa para referência (Adaptado de Mota, 2007).

Figura 4

Mapa de Anomalias Bouguer completa, ou seja, com todas as correções aplicadas. Valores em mGal. Os contatos litológicos estão plotados no mapa para referência (Adaptado de Mota, 2007).

tiva, conclui-se que o polinômio de grau 1 é melhor para representar o regional, por não gerar valores discrepantes nas bordas, pois, no ponto de vista geológi-

\section{Cálculo de densidade}

As amostras, para os ensaios de densidade, foram coletadas principalmente nas pedreiras contidas do maciço e em raras exposições de rocha sã, visto que há necessidade de que as amostras não portem processos de intemperismo químico. Num universo de 31 densidades obtidas de rochas alcalinas, o valor

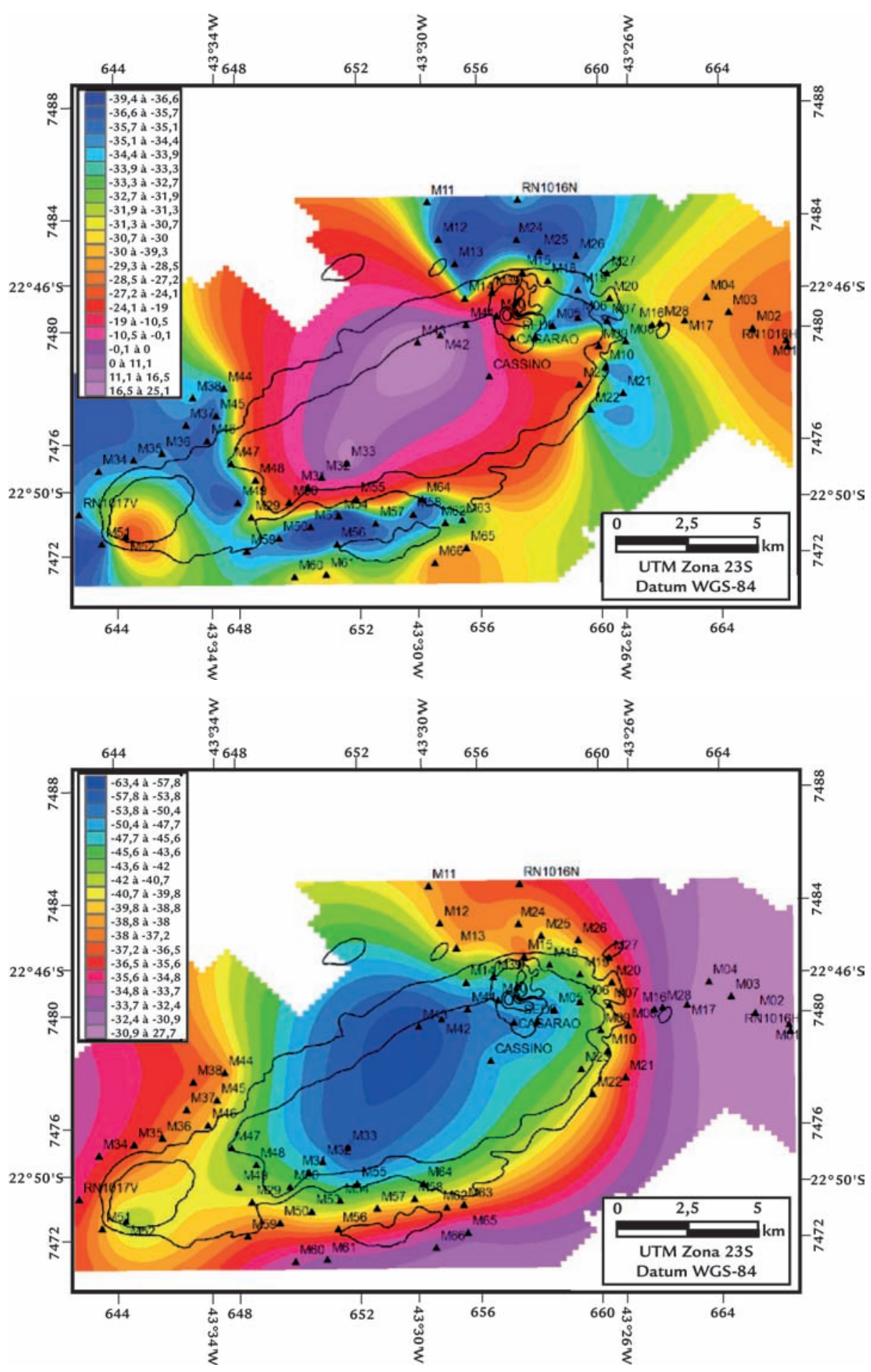

co, não há justificativa para a presença desses valores.

Os perfis $\mathrm{AB}$ e $\mathrm{CD}$ foram escolhidos de forma que cortassem as áreas

da média aritmética é $2,53 \mathrm{~g} / \mathrm{cm}^{3}$, a mediana/média interna $2,54 \mathrm{~g} / \mathrm{cm}^{3}$ e moda $2,55 \mathrm{~g} / \mathrm{cm}^{3}$.

A quase igualdade desses valores implica uma distribuição regular. Qualquer um desses valores de densidades poderia ser usado para a modelagem como representante das rochas alcalinas. $\mathrm{O}$ va- mais significativas e com um maior número de pontos coletados, como a área do "Vulcão de Nova Iguaçu" e o maciço Marapicu. 


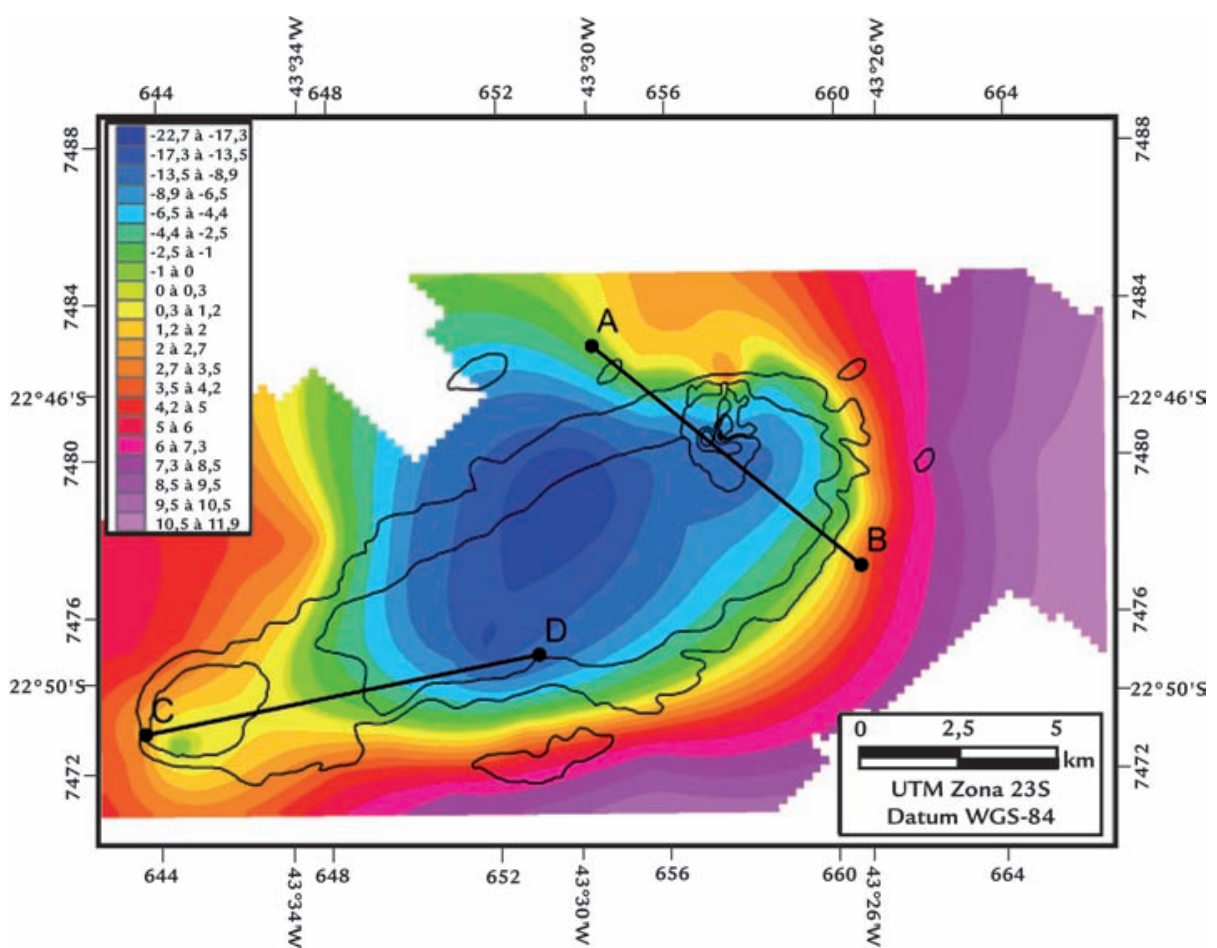

chas alcalinas, pode propiciar pequenas variações nos valores de densidade. Rochas com maiores concentrações de biotita $\left(\rho=2,8-3,2 \mathrm{~g} / \mathrm{cm}^{3}\right)$ e anfibólio $\left(\rho=3,0-3,4 \mathrm{~g} / \mathrm{cm}^{3}\right)$ tendem a ser mais densas. Algumas fácies traquíticas sulfetadas também podem apresentar características semelhantes: em duas amostras, há maior concentração de sulfetos, como a pirita $\left(\rho=5,02 \mathrm{~g} / \mathrm{cm}^{3}\right)$

\section{Modelagem Direta 2,5D}

Para o processo de modelagem, considerou-se que o Complexo Alcalino do Mendanha tem densidade de 2,54 g/ $\mathrm{cm}^{3}$ (valor da média interna/mediana), correspondente a rochas traquíticas ou sieníticas, compostas, predominantemente, de feldspatos alcalinos (aproximadamente 2,52 $\mathrm{g} / \mathrm{cm}^{3}$ - Klein \& Dutrow, 2008), contendo minerais máficos e, raramente, sulfetos associados. Por outro lado, a rocha encaixante possui densidade média de $2,68 \mathrm{~g} / \mathrm{cm}^{3}$, correspondente aos biotita gnaisses, predominantes na região, o que implica um contraste de densidade de $0,14 \mathrm{~g} / \mathrm{cm}^{3}$. A discrepância observada, nas bordas nos perfis de anomalia residual, é relacionada a não consideração dos efeitos gravitacionais de grandes volumes de corpos rochosos, como a serra da Mantiqueira.

\section{Discussões e conclusões}

Os resultados mostraram que a integração entre os dados geológicos e gra- e a calcopirita $\left(\rho=5,25 \mathrm{~g} / \mathrm{cm}^{3}\right)$. Os valores de densidades dos minerais foram retirados de Klein e Dutrow (2008). Outro fator que pode também ser considerado é a presença de vesículas, que, neste caso, pode diminuir o valor de densidade da rocha, devido à quantidade de espaços vazios contidos.

As rochas encaixantes apresentaram um padrão aleatório, devido à
O perfil AB, mostrado na Figura 5, modelado da região do vulcão de Nova Iguaçu, apresenta uma estrutura de forma triangular invertida, lembrando um funil, com, aproximadamente, $20 \mathrm{~km}$ de profundidade (Figura 6). Outro polígono, inserido dentro dessa estrutura, de menor largura (aproximadamente 300$700 \mathrm{~m}$ ), possui valores menores de densidade, apresentando um formato colunar, sendo mais largo em porção aflorante.

Esse polígono menor foi acrescentado devido à necessidade de ajuste da curva da anomalia calculada, o que não permitiria alcançar valores observados tão baixos de anomalia gravimétrica residual, ou seja, mesmo que se atribuísse, para todo o maciço, o valor de densidade média de $2,54 \mathrm{~g} / \mathrm{cm}^{3}$, não seria possível explicar a grande anomalia negativa, na vimétricos promoveram um conhecimento consistente da estrutura do Complexo

\section{Figura 5}

Mapa de anomalia residual obtida a partir de superfície polinomial de grau 1 e localização dos perfis selecionados $A B$ e $\mathrm{CD}$, para modelagem.

variação composicional das bandas. As bandas máficas do biotita gnaisse, com valores entre $2,70 \mathrm{~g} / \mathrm{cm}^{3}$ e $2,85 \mathrm{~g} / \mathrm{cm}^{3}$, são mais densas que as bandas quatrzo-feldspáticas $(2,59 \mathrm{~g} /$ $\mathrm{cm}^{3}$ a 2,64 $\mathrm{g} / \mathrm{cm}^{3}$ ), num universo de 8 amostras. O valor adotado para a representação das rochas encaixantes corresponde ao valor médio obtido $\left(2,68 \mathrm{~g} / \mathrm{cm}^{3}\right)$. região central do perfil. A curva de densidade apresentou uma grande queda e só foi ajustada corretamente quando foi inserido um polígono, com densidade de, aproximadamente, $2,46 \mathrm{~g} / \mathrm{cm}^{3}$, associado a rochas piroclásticas e diques de traquitos portadoras de espaços intersticiais.

Na Figura 7, o perfil CD modelado da Figura 5, representando a região do morro do Marapicu, apresenta uma estrutura rasa, de geometria convexa, com, aproximadamente, $400 \mathrm{~m}$ de profundidade. Entre o Marapicu e o Mendanha, onde foi encontrada rocha gnáissica, a anomalia calculada conseguiu se ajustar com taxa de erros relativamente pequena, sugerindo que os polígonos que representam as rochas alcalinas do $\mathrm{Ma}$ rapicu e o Mendanha são distintos.
Alcalino do Mendanha, em termos regionais. A aplicação do método gravimé- 
Figura 6

Acima, modelo gerado a partir dos sinais gravimétricos para o perfil $A B$ do Complexo Intrusivo do Mendanha. Abaixo, as curvas da anomalia calculada (linha sólida) com a anomalia observada (linha pontilhada).

Figura 7

Acima, modelo gerado a partir dos sinais gravimétricos para o perfil CD do Complexo Alcalino do Mendanha. Abaixo, as curvas da anomalia calculada (linha sólida) com a anomalia observada (linha pontilhada).

trico, para a área, contribuiu para definir a forma geométrica da intrusão alcalina, o que permitiu determinar a sua posição atual de denudação.

$\mathrm{Na}$ localidade descrita por Klein et al. (1984) como "Vulcão de Nova Iguaçu", a modelagem gravimétrica mostra um corpo alcalino com forma de funil, de densidade média $2,54 \mathrm{~g} / \mathrm{cm}^{3}$, com, aproximadamente, $2,5 \mathrm{~km}$ de largura, e que contém outra estrutura menor, de aspecto colunar e com densidade menor, em torno de 2,46 g/ $\mathrm{cm}^{3}$. De acordo com a descrição anteriormente apresentada, essa estrutura colunar pode ser associada a brechas piroclásticas, visto que elas são compostas por fragmentos de rochas
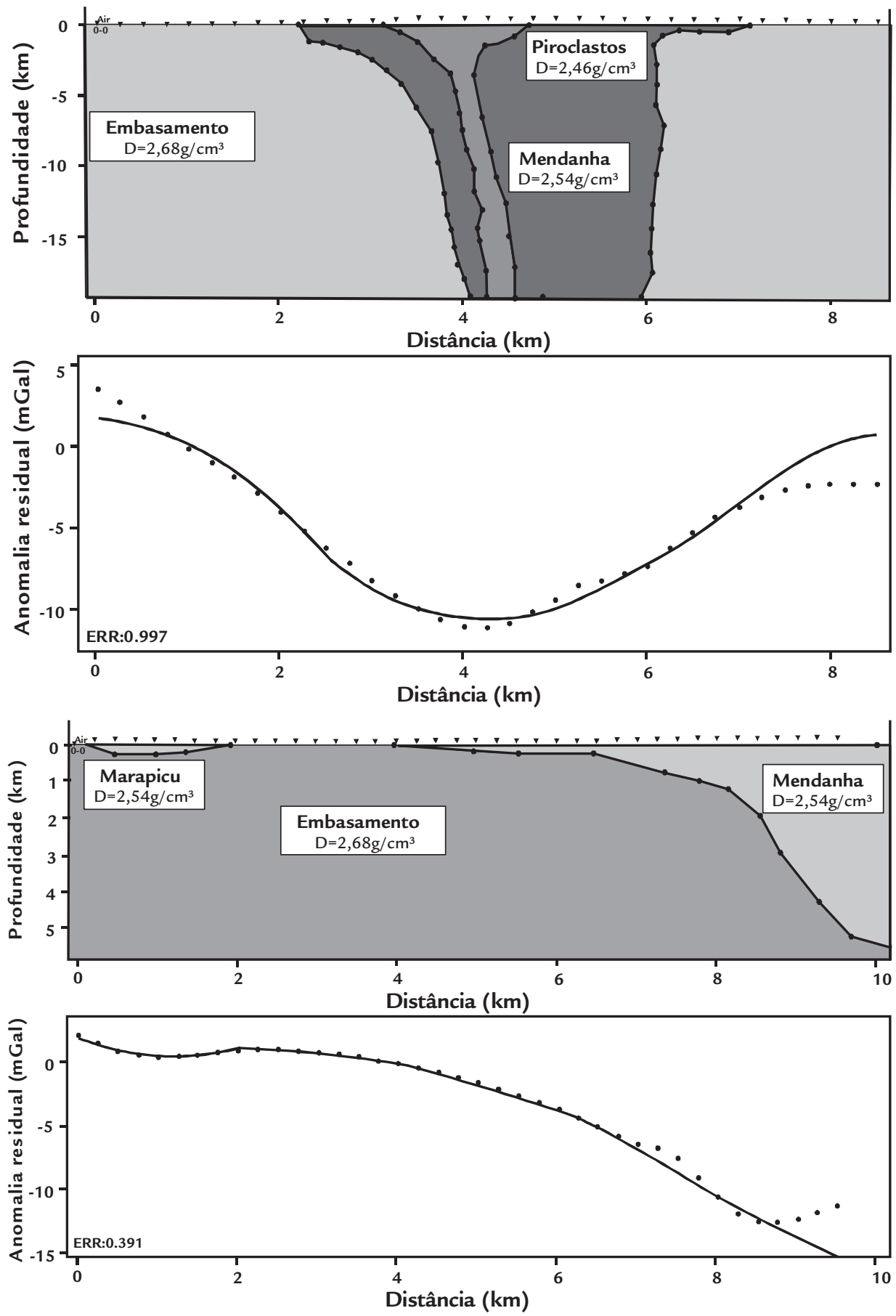

traquíticas em diversas granulometrias. Essa estrutura colunar mostra o comportamento da fácies piroclásticas como uma espécie de conduto extrusivo, com largura entre 300 e $700 \mathrm{~m}$.

$\mathrm{Na}$ região do morro do Marapicu, foi possível a individualização dos corpos do Marapicu e Mendanha. Em subsuperfície, o Marapicu caracteriza-se por um testemunho de uma intrusão alcalina, de, aproximadamente, $400 \mathrm{~m}$ de profundidade, em relação ao nível do terreno, ou seja, o corpo pode ser associado a uma antiga continuidade da intrusão alcalina do Mendanha.

Em conclusão, o Complexo Alcalino do Mendanha possui um nível avançado de denudação, que levou à exposição da câmara magmática, com um conduto subvulcânico e possíveis diques alimentadores. $\mathrm{Na}$ região do Marapicu, a denudação foi tão intensa que formou uma janela estrutural entre o Marapicu e o Mendanha, com exposição de rochas gnáissicas. Os diques alcalinos encontrados representam os diques alimentadores do magmatismo alcalino. Os resultados de gravimetria refutam a hipótese de edifício vulcânico preservado e tal hipótese é confirmada por caracterizações vulcanológicas e geomorfológicas (Motoki et al., 2007a, 2007b, 2008a, 2008b, Petrakis et al., 2010). 


\section{Referências bibliográficas}

ALMEIDA, F. F. M. Relações tectônicas das rochas alcalinas mesozoicas da região meridional da Plataforma Sul-Americana. Revista Brasileira de Geociências, v. 13, n. 3, p. 139-158, 1983.

AMARAL, G., BUSHEE, J., CORDANI, U.G., KAWASHITA, K., REYNOLDS, J.H. Potassium-argon ages of alkaline rocks from southern Brazil. Geochimica et Cosmochimica Acta, v. 31, p. 117-142, 1967.

ARANA, J. O uso do GPS na determinação de altitudes ortométricas. In: CONGRESSO BRASILEIRO DE CADASTRO TÉCNICO MULTIFINALITÁRIO, 6. Anais... Florianópolis, 2004, CD-ROM.

ARENA, M. C., SILVEIRA L.S., DUTRA, T. CORVAL, A., VALENTE, S.C. Geologia e Petrologia dos Traquitos e Sienitos da Pedreira Vigné, Nova Iguaçu, RJ. In: SIMPÓSIO DE VULCANISMO E AMBIENTES ASSOCIADOS, 3. Anais... Rio de Janeiro, Cabo Frio: SBG, 2005, p. 109-114.

DUTRA T. Mapeamento geológico e petrografia das rochas aflorantes na área de lavra da Pedreira Vigné e adjacências, Nova Iguaçu, RJ. Universidade Federal Rural do Rio de Janeiro, 2004. 77p. (Monografia - Graduação),

ESRI ArcGIS, versão 9.3: ESRI, 2008. Suíte de aplicativos para GIS. 1 CD-ROM.

GEOSOFT Oasis Montaj Standard Edition, versão 6.4.2. GEOSOFT, 2007, 1 CD-ROM. KLEIN, C., DUTROW, B. Manual of Minseral Science. New Jersey: Wiley, 2008, 675p.

KLEIN, V. C., VALENÇA, J. G., VIEIRA, A. C., Ignimbritos do vulcão de Nova Iguaçu e da "Chaminé do Lamego", Rio de Janeiro. In: CONGRESSO BRASILEIRO DE GEOLOGIA, 33. Anais... Rio de Janeiro, SBG, 1984, p. 4346-4354.

KLEIN, V. C. O vulcão de Nova Iguaçu (Estado do Rio de Janeiro): Controle estrutural e processo de erupção. Rio de Janeiro: Instituto de Geociências, Universidade Federal do Rio de Janeiro, 1993. 108p. (Tese de Doutorado).

MOTA, C. E. M., ALVES, A. P. R. Condicionantes do relevo do Maciço Mendanha, Nova Iguaçu - RJ - Resultados preliminares In: CONGRESSO BRASILEIRO DE GEOLOGIA, 43. Anais... Aracaju, SBG, 2006, p. 268

MOTA, C. E. M., GERALDES, M. C., A classificação de brechas magmáticas e sua implicação na evolução do Complexo Alcalino de Nova Iguaçu - RJ. Geociências, v.25, n. 1, p. 37-48, 2006.

MOTA, C. E. M. Estudo geológico e gravimétrico do Complexo Marapicu-GericinóMendanha - Rio de Janeiro. Rio de Janeiro: Programa de Pós-Graduação em Análise de Bacias e Faixas Móveis, Faculdade de Geologia, Universidade do Estado do Rio de Janeiro, 2007. 127p. (Dissertação de Mestrado).

MOTA, C. E. M., SOUSA, M. A., GERALDES, M. C., MANE, M. A. Modelagem direta 2,5D da região do "Vulcão de Nova Iguaçu" e da "Chaminé do Lamego", baseada em informações geológicas, gravimétricas e petrofísicas. In: SIMPÓSIO DE VULCANISMO E AMBIENTES ASSOCIADOS, 4. Anais... Foz do IguaçuPR. SBG/PR, 2008 CD-ROM.

MOTOKI, A., SICHEL, S. E. Avaliação de aspectos texturais e estruturais de corpos vulcânicos e subvulcânicos e sua relação com o ambiente de cristalização, com base em exemplos do Brasil, Argentina e Chile. REM - Revista Escola de Minas, v. 59, n. 1, p. 13-23, 2006.

MOTOKI, A., SOARES, R., NETTO, A. M., SICHEL, S. E., AIRES, J. R., LOBATO, M., Reavaliação do modelo genético do Vulcão de Nova Iguaçu, RJ: origem eruptiva ou intrusão subvulcânica? REM - Revista Escola de Minas, v. 60 n. 4, p. $1-10,2007 a$.

MOTOKI, A., SOARES, R., NETTO, A. M., SICHEL, S. E., AIRES, J. R., LOBATO, $\mathrm{M}$. Forma de ocorrência geológica dos diques de rocha piroclástica no Vale do Rio Dona Eugênia, Parque Municipal de Nova Iguaçu, RJ. Geociências, v. 26, n. 1, p. 67-82. 2007b.

MOTOKI, A., SOARES, R., LOBATO, M., SICHEL, S. E., AIRES, J. R. Feições intempéricas em rochas alcalinas félsicas de Nova Iguaçu, RJ. REM- Revista Escola de Minas, v. 60, n. 3, p. 451-458, 2007c.

MOTOKI, A., PETRAKIS, G. H., SICHEL, S. E., CARDOSO, C. E., MELO, R. C., SOARES, R., MOTOKI, K. F. Origem dos relevos do Maciço Sienítico do Mendanha, RJ, com base nas análises geomorfológicas e sua relação com a hipótese do Vulcão de Nova Iguaçu. Geociências, v. 27, n. 1, p. 99-115, 2008 a. 
MOTOKI, A., SICHEL, S. E., SOARES, R. S., AIRES, J. R., SAVI, D. C., PETRAKIS, G. H., MOTOKI, K. F. Rochas piroclásticas de preenchimento de condutos subvulcânicos do Mendanha, Itaúna e Ilha de Cabo Frio, RJ, e seu processo de formação com base no modelo de implosão de conduto. Geociências, v. 27, n. 3, p. 451-467, 2008b.

PETRAKIS, G. H., MOTOKI, A., SICHEL, S. E., ZUCCO, L. L., AIRES, J. R., MELLO S. L. M. Ore geology of special quality gravel and artificial sand: exemples of alkaline syenite of Nova Iguaçu, State of Rio de Janeiro, and rhyolite of Nova Prata, State of Rio Grande do Sul, Brazil. Geociências, v. 29, n. 1, p. 21-32, 2010.

SICHEL, S. E., MOTOKI, A., SAVI, D. C., SOARES, R. S. Subvolcanic vent-filling welded tuff breccia of the Cabo Frio Island, State of Rio de Janeiro, Brazil. REM Revista Escola de Minas, v. 61, n. 4, p. 423-432, 2008.

SILVEIRA, L. S., DUTRA T., VALENTE S. C., RAGATKY, C. D. Modelos Eruptivos Preliminares para o Complexo Vulcânico de Nova Iguaçu, RJ. In: SIMPÓSIO DE VULCANISMO E AMBIENTES ASSOCIADOS, 3. Anais... Rio de Janeiro: SBG, 2005, p. 333-337.

SONOKI, I. K., GARDA, G. M. Idades K-Ar de rochas alcalinas do Brasil meridional e Paraguai oriental: compilação e adaptação às novas constantes de decaimento. Boletim IG-USP, Série Científica, v. 19 p. 63-85, 1988.

TALWANI, M., WORZEL, J., LANDISMAN, M. Rapid Gravity computations for two dimensional bodies with application to the Mendocino Submarine fracture zone. Journal of Geophysical Ressearch, v. 64, p. 49-59, 1959.

VAlENTE, S. C., MELLO, E. F., PALERMO, N. Geologia de uma porção do complexo vulcânico de Nova Iguaçu limitrofe à área de lavra da pedreira Vigné, Nova Iguaçu, RJ. Nova Iguaçu: Ministério Público, 2005. 72p. (Relatório final inédito).

USGS. Earth Explorer. Disponível em <http://earthexplorer.usgs.gov/>. Acesso em: 10 out 2010.

Artigo recebido em 11 de agosto de 2011. Aprovado em 27 de agosto de 2012. 